\title{
Prevalence and Prediction of Exercise-Induced Oxygen Desaturation in Patients with Chronic Obstructive Pulmonary Disease
}

\author{
A.J.R. van Gestel ${ }^{\mathrm{a}-\mathrm{c}} \quad$ C.F. Clarenbach ${ }^{\mathrm{a}} \quad$ A.C. Stöwhas ${ }^{\mathrm{a}} \quad$ S. Teschler ${ }^{\mathrm{C}} \quad$ E.W. Russi ${ }^{\mathrm{a}}$ \\ H. Teschler ${ }^{c}$ M. Kohler ${ }^{a}$ \\ a Pulmonary Division, University Hospital of Zurich, Zurich, and ${ }^{b}$ Department of Health, Zurich University of \\ Applied Sciences, Winterthur, Switzerland; 'Department of Pneumology, University Hospital Ruhrlandklinik, \\ Essen, Germany
}

\author{
Key Words \\ Chronic obstructive pulmonary disease $\cdot$ Exercise-induced \\ oxygen desaturation $\cdot$ Forced expiratory volume in \\ one second $\cdot$ Diffusion capacity for carbon monoxide $\cdot$ \\ 6-minute walking test
}

\begin{abstract}
Background: Previous studies with small sample sizes reported contradicting findings as to whether pulmonary function tests can predict exercise-induced oxygen desaturation (EID). Objective: To evaluate whether forced expiratory volume in one second $\left(\mathrm{FEV}_{1}\right)$, resting oxygen saturation $\left(\mathrm{SpO}_{2}\right)$ and diffusion capacity for carbon monoxide (DLCO) are predictors of EID in chronic obstructive pulmonary disease (COPD). Methods: We measured FEV $1, \mathrm{DLCO}_{1} \mathrm{SpO}_{2}$ at rest and during a 6-min walking test as well as physical activity by an accelerometer. A drop in $\mathrm{SpO}_{2}$ of $>4$ to $<90 \%$ was defined as EID. To evaluate associations between measures of lung function and EID univariate and multivariate analyses were used and positive/negative predictive values were calculated. Receiver operating characteristic curve analysis was performed to determine the most useful threshold in order to predict/exclude EID. Results: We included 154 patients with COPD (87 females). The mean $\mathrm{FEV}_{1}$ was $43.0 \%$ (19.2) predict-
\end{abstract}

ed and the prevalence of EID was $61.7 \%$. The only independent predictor of EID was $\mathrm{FEV}_{1}$ and the optimal cutoff value of FEV ${ }_{1}$ was at $50 \%$ predicted (area under ROC curve, 0.85 ; $p<0.001)$. The positive predictive value of a threshold of $\mathrm{FEV}_{1}<50 \%$ was 0.83 with a likelihood ratio of 3.03 and the negative predicting value of a threshold of $\mathrm{FEV}_{1} \geq 80 \%$ was 1.0. The severity of EID was correlated with daily physical activity $(r=-0.31, p=0.008)$. Conclusions: EID is highly prevalent among patients with COPD and can be predicted by $\mathrm{FEV}_{1}$. EID seems to be associated with impaired daily physical activity which supports its clinical importance.

Copyright $\odot 2012$ S. Karger AG, Basel

\section{Introduction}

Chronic obstructive pulmonary disease (COPD) is characterized by a gradual loss of lung function with airway obstruction that is not fully reversible [1]. Advanced COPD is associated with reduced exercise tolerance, resulting in impaired health-related quality of life [2], high health care use [3] and increased mortality [4]. Therefore, exercise testing is progressively being considered an essential component in the routine clinical assessment of patients with COPD.

\section{KARGER \\ Fax +4161306 1234 \\ E-Mail karger@karger.ch}

www.karger.com (c) 2012 S. Karger AG, Basel

$0025-7931 / 12 / 0845-0353 \$ 38.00 / 0$

Accessible online at:

www.karger.com/res
Dr. rer. medic. Arnoldus J.R. van Gestel

Zurich University of Applied Sciences

Technikumstrasse 71

$\mathrm{CH}-8401$ Winterthur (Switzerland)

Tel. +41 5893463 28, E-Mail vrns@zhaw.ch 
Hypoxemia at rest is an important complication in patients with COPD [5], potentially causing dyspnea and other deleterious effects such as pulmonary hypertension with the development of right ventricular hypertrophy, polycythemia [6], cardiovascular disorders [7], inflammatory cytokine production [8] and hypoxia-induced multiorgan dysfunction. Hypoxemia of less than $7.3 \mathrm{kPa}$ or oxygen saturation $\left(\mathrm{SpO}_{2}\right)$ of less than $88 \%$ is considered an established indication for oxygen supplementation [911]. However, some patients do not meet these criteria during rest, but significant oxygen desaturation occurs during exertion [12]. Earlier studies have suggested that deterioration of $\mathrm{SpO}_{2}$ during physical exercise is associated with increased risk of mortality in patients with COPD $[13,14]$. Nonetheless, exercise-induced desaturation (EID) remains a topic of interest and prediction of EID could be useful for the clinical management of COPD patients to ensure maintenance of normoxemia during physical activity and elude potential adverse consequences of hypoxemia.

Clinical criteria to predict EID may help physicians caring for COPD patients to reduce the prevalence of unrecognized EID among patients with COPD without unnecessary diagnostic testing. Only a few studies addressed this topic $[15-17,19,20]$. These studies reported contradicting findings as to whether pulmonary function parameters, such as forced expiratory volume in one second $\left(\mathrm{FEV}_{1}\right)$ and diffusion capacity for carbon monoxide (DLCO) as well as resting $\mathrm{SpO}_{2}$, can predict EID. Some of these studies found that $\mathrm{FEV}_{1}$, DLCO and resting $\mathrm{SpO}_{2}$ can be used as screening tests to predict EID $[12,13,19,20]$, but others failed to identify those or other variables as predictors $[5,15,18]$.

Patients with COPD experience EID in an unpredictable fashion; patients exhibit variability in the magnitude and temporal onset of EID with a mbulation, which makes it difficult to find reliable predictors as to whether patients will desaturate during exercise $[17,20]$. Given the limitations and conflicting results of previous studies, the purpose of the present study was to determine the prevalence of EID, to analyze the oxygen desaturation pattern and to investigate whether FEV $\mathrm{F}_{1}$, DLCO and resting $\mathrm{SpO}_{2}$ are associated with EID in a large number of patients with COPD of different severity. Furthermore, we wished to investigate whether EID is associated with daily physical activity.

\section{Methods}

\section{Study Subjects}

Patients with COPD referred to the Department of Respiratory Medicine, Ruhrlandklinik, University of Duisburg-Essen, Germany between November 2008 and July 2009 and to the Pulmonary Division, University Hospital of Zurich, Switzerland between November 2009 and November 2010 were considered for participation in the study. The inclusion criteria for patients were: male/female subjects aged 40-75 years, confirmed COPD according to GOLD guidelines [1]. The exclusion criteria were: acute or recent (within last 6 weeks) exacerbation of COPD according to GOLD guidelines [1], patients on long-term oral corticosteroids or morphine medication, mental or physical disability precluding informed consent or compliance with the protocol. The study was approved by the Research Ethics Committee of the Medical Faculty, University of Essen-Duisburg (No. 07-3524) and Zurich (No. EK-1734), and written informed consent was obtained from all patients.

\section{Measurements}

Pulmonary Function

Spirometry, whole-body plethysmography and diffusion capacity measurements were performed according to the American Thoracic Society (ATS) and the European Respiratory Society guidelines with a commercially available system [21, 22].

\section{Six-Minute Walk Test}

Patients performed the 6-min walk test (6MWT) following pulmonary function testing. 6MWT distance was measured according to the guidelines of the ATS [23]. Additionally, scored sensations of breathlessness and leg fatigue were assessed using a Borg scale [23]. Measurements of $\mathrm{SpO}_{2}$ were performed using a finger pulse oximeter (TuffSat ${ }^{\mathrm{TM}}$, Datex Ohmeda, Madison, Wisc., USA, and PureLight ${ }^{\circledR} 8000$, Nonin Medical Inc., Hudiksvall, Sweden). $\mathrm{SpO}_{2}$, dyspnea and leg fatigue were assessed after a resting period of 5 min immediately before the beginning of the 6MWT and immediately after the test. The $6 \mathrm{MWT}$ was performed on a 30 -meter indoor track by an experienced investigator using standardized encouragement strategy [24]. None of the patients used a walking aid in daily life or during the test. EID was defined as a $\mathrm{SpO}_{2}$ fall of $>4$ to $<90 \%$ during the $6 \mathrm{MWT}[19,25]$. EID was calculated by the following formula: $\left(\mathrm{SpO}_{2}\right.$ at rest $-\mathrm{SpO}_{2}$ on exertion) $/ \mathrm{SpO}_{2}$ at rest $\times 100$.

\section{Oxygen Desaturation Pattern}

In a subset of 43 patients recruited at the Pulmonary Division, University Hospital of Zurich, $\mathrm{SpO}_{2}$ was continuously recorded before, during and after the 6MWT using a fingerpulse oximeter with a sample rate of $128 \mathrm{~Hz}$ (Nexus-10 ${ }^{\mathrm{TM}}$, TMS International BV, Enschede, The Netherlands, and PureLight ${ }^{\circledR} 8000$, Nonin Medical Inc.) in order to describe oxygen desaturation patterns of COPD patients with GOLD stages I/II and III/IV.

\section{Physical Activity}

A multisensor armband (SenseWear Pro ${ }^{\mathrm{TM}}$; BodyMedia Inc., Pittsburgh, Pa., USA) monitor which is worn on the upper right arm over the triceps muscle was used to measure daily physical activity in a subset of 64 patients recruited at the Pulmonary Division, University Hospital of Zurich. It incorporates a biaxial ac- 
celerometer that records steps per day, physiological indicators of energy expenditure and physical activity duration. Participants were instructed to wear the accelerometer during 7 days, except when bathing or showering. The SenseWear Pro ${ }^{\mathrm{TM}}$ armband provides a valid and reliable estimate of patients' average number of steps per day/24 h [26].

\section{Data Analysis}

A statistical software package was used for all calculations (SPSS for Windows, version 11.0; SPSS Inc., Chicago, Ill., USA). Descriptive data for continuous variables are expressed as means and standard deviation. To determine a possible correlation between EID and daily physical activity, Pearson's correlation was used. An independent $t$ test was used for comparison of EID between patients with GOLD stages I/II and III/IV. Univariate (Pearson's correlation) and multivariate analyses were performed to assess the associations between EID and airflow limitation $\left(\mathrm{FEV}_{1}\right)$, diffusing capacity (DLCO) and resting $\mathrm{SpO}_{2}$. Other variables reflecting pathophysiologic features of COPD such as lung hyperinflation (RV/TLC), total lung capacity (TLC) and anthropometrical characteristics (BMI) were also included in the analysis. Variables which significantly correlated with EID in the univariate analysis were included in the multivariate analysis. Receiver operating characteristic (ROC) curve analysis was undertaken to determine the optimal cutoff value for predicting EID. The positive predictive value (PPV) and the negative predictive value (NPV) were calculated. To determine a possible association between EID and daily physical activity, univariate analysis (Pearson's correlation) was used. A p value of $<0.05$ was considered to be significant.

\section{Results}

\section{Patients' Characteristics}

One hundred and fifty-four patients with COPD (GOLD class I-IV) agreed to take part and were included in the study. Anthropometrical characteristics, pulmonary function, respiratory symptoms and exercise capacity data of the 154 patients ( 87 females) with COPD are presented in table 1 . COPD was mild (GOLD I) in $0 \%$ of the patients, moderate (GOLD II) in $7.1 \%$ of the patients, severe (GOLD III) in $26.6 \%$ of the patients and very severe (GOLD IV) in $27.9 \%$ of the patients.

\section{Prevalence of EID and $\mathrm{O}_{2}$ Desaturation Patterns}

In total, 95 of the 154 (61.7\%) patients experienced EID during the 6MWT. The prevalence of EID according to GOLD stages is shown in figure 1.

Figure 2 shows $\mathrm{SpO}_{2}$ immediately before, during and after the 6MWT in patients with COPD in GOLD stages I/II and III/IV. $\mathrm{SpO}_{2}$ deteriorated within the first $3 \mathrm{~min}$ of the $6 \mathrm{MWT}$ before reaching a plateau from the 4 th to the 6 th minute of the test. Oxygen desaturation was more pronounced in patients with GOLD stages III/IV (11.3 \pm
Table 1. Anthropometrics, pulmonary function, respiratory symptoms, cardio-pulmonary exercise capacity and physical activity

\begin{tabular}{|c|c|}
\hline Variable & Mean $\pm S D$ \\
\hline \multicolumn{2}{|l|}{ Anthropometrics } \\
\hline Subjects & 154 \\
\hline Female/male & $87 / 67$ \\
\hline Age, years & $62.5 \pm 10.7$ \\
\hline BMI & $24.9 \pm 6.1$ \\
\hline \multicolumn{2}{|l|}{ Pulmonary function } \\
\hline $\mathrm{FEV}_{1}$, liters & $1.21 \pm 0.49$ \\
\hline $\mathrm{FEV}_{1}, \%$ predicted & $43 \pm 19$ \\
\hline $\mathrm{FEV}_{1} / \mathrm{IVC}$ & $0.5 \pm 0.2$ \\
\hline DLCO, \% predicted & $51 \pm 23$ \\
\hline TLC, \% predicted & $116 \pm 23$ \\
\hline RV/TLC & $0.57 \pm 0.12$ \\
\hline \multicolumn{2}{|c|}{ Cardiopulmonary exercise capacity } \\
\hline 6MWD, m & $452 \pm 106$ \\
\hline $\mathrm{SpO}_{2}, \%$ at rest & $94.3 \pm 2.9$ \\
\hline $\mathrm{SpO}_{2}, \%$ post exercise & $86.4 \pm 6.8$ \\
\hline $\mathrm{SpO}_{2}, \%$ desaturation & $8.4 \pm 6.5$ \\
\hline Dyspnea at rest, $0-10$ & $1.0 \pm 1.1$ \\
\hline Dyspnea after, $0-10$ & $4.5 \pm 2.2$ \\
\hline Leg fatigue at rest, $0-10$ & $0.4 \pm 0.4$ \\
\hline Leg fatigue after, $0-10$ & $3.1 \pm 2.2$ \\
\hline \multicolumn{2}{|l|}{ Physical activity $(\mathrm{n}=64)$} \\
\hline Steps $/ 24 \mathrm{~h}$ & $6,112 \pm 3,332$ \\
\hline
\end{tabular}

6.3\%) compared to patients with GOLD stages I/II (4.2 \pm $4.7 \%)(\mathrm{p}<0.001)$. The $\mathrm{SpO}_{2}$ curve of patients with GOLD stages III/IV showed a steeper decline and slower recovery compared to patients with GOLD stages I/II. The $\mathrm{SpO}_{2}$ of patients in GOLD stages I/II reached a full recovery within $1 \mathrm{~min}$ after the 6MWT.

\section{Determinants of Exercise-Induced Desaturation}

There was a significant positive correlation between the severity of EID and RV/TLC and TLC. A significant negative correlation was found between the severity of EID and $\mathrm{SpO}_{2}$ at rest, $\mathrm{FEV}_{1}$, DLCO and BMI (table 2; fig. 3).

A multiple linear regression analysis which included all variables with significant correlations in the univariate analysis was performed and the results are shown in table 3. Variables with high intercorrelations with $\mathrm{FEV}_{1}$ (RV/TLC and TLC) were removed from the analysis. Only $\mathrm{FEV}_{1}$ was found to be significantly and independently associated with EID. EID can be estimated with the predictive formula: $\mathrm{EID}(\%)=-0.19 \mathrm{FEV}_{1}$ (\%predicted) +16.6 . 


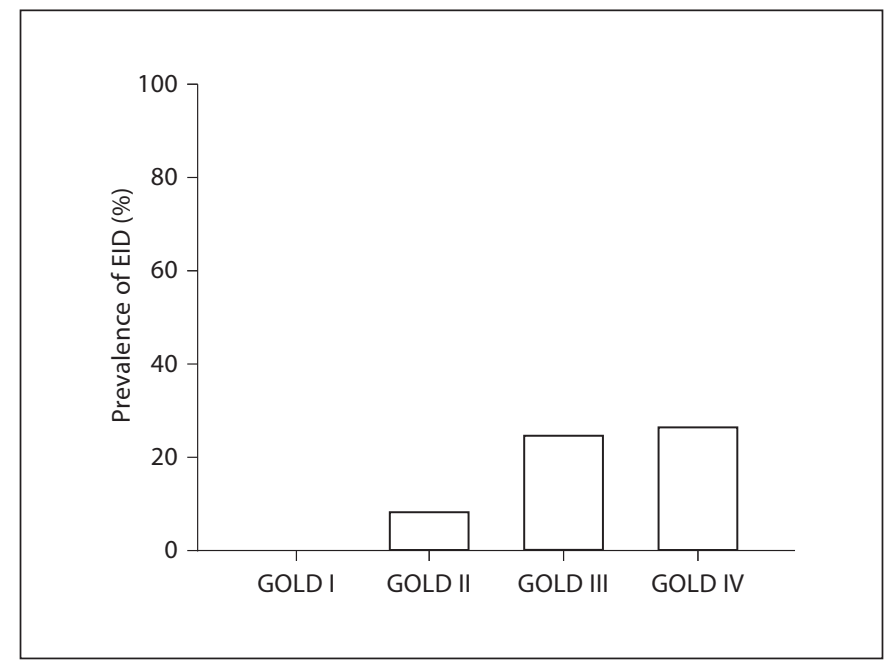

Fig. 1. Prevalence of EID during the 6MWT in patients with COPD grouped according to GOLD stages: GOLD IV 27.9\%, GOLD III 26.6\%, GOLD II 7.1\% and GOLD I 0\%.

Table 2. Correlations with exercise-induced desaturation

\begin{tabular}{llc}
\hline Variable & Coefficient $\mathrm{r}$ & p value \\
\hline $\mathrm{SpO}_{2}$ at rest, \% & -0.19 & 0.02 \\
$\mathrm{FEV}_{1}, \%$ predicted & -0.62 & $<0.001$ \\
DLCO, \% predicted & -0.53 & $<0.001$ \\
$\mathrm{BMI}$ & -0.28 & 0.001 \\
RV/TLC, \% predicted & 0.52 & $<0.001$ \\
TLC, \% predicted & 0.38 & $<0.001$
\end{tabular}

Correlation is expressed as Pearson's correlation coefficient.

Accuracy of Different FEV $V_{1}$ Levels as Cutoff Values

ROC curve analysis (fig. 4) confirmed that the best combination of sensitivity and specificity to predict EID occurred at an $\mathrm{FEV}_{1}$ value of $50 \%$ (area under the ROC curve $0.85 ; p<0.001)$.

As demonstrated in table 4,84 of the 95 patients with EID had a $\mathrm{FEV}_{1}$ of less than $50 \%$ (sensitivity, 88.4\%); however, 42 of 59 patients without EID had a $\mathrm{FEV}_{1}$ of $50 \%$ or more (specificity, $71.2 \%$ ). The positive predictive value of a threshold of $\mathrm{FEV}_{1}<50 \%$ was 0.83 . The likelihood ratio with $\mathrm{FEV}_{1}<50 \%$ was 3.03 . The negative predicting value for $\mathrm{FEV}_{1}>80 \%$ was 1.0. The likelihood ratio with $\mathrm{FEV}_{1}$ $>80 \%$ was 1.14 .

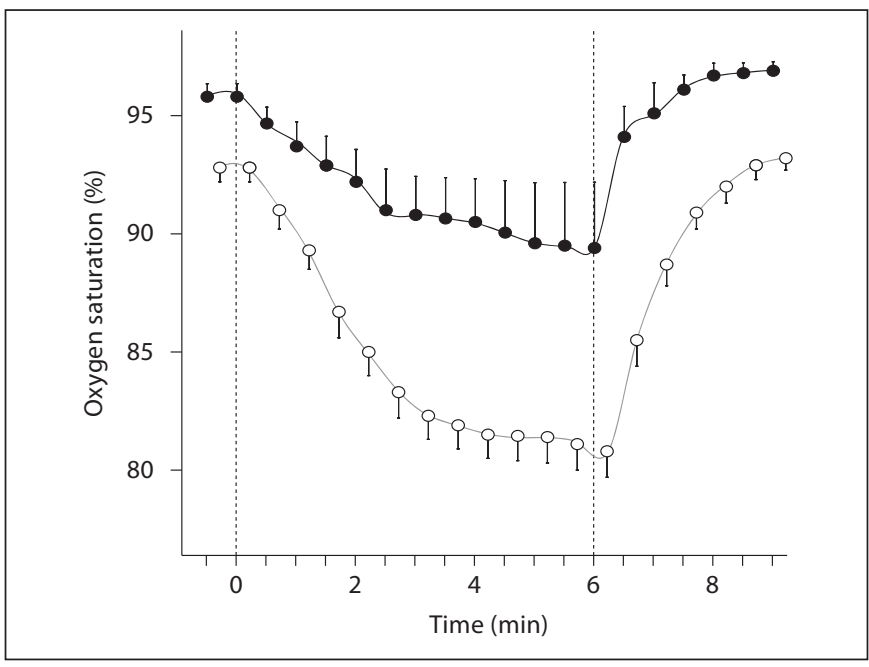

Fig. 2. $\mathrm{SpO}_{2}$ of patients with GOLD stages I/II (black dots) and III/ IV (white dots) during the 6MWT and the recovery period. Both groups reached a $\mathrm{SpO}_{2}$ plateau within 3-4 min; the $\mathrm{SpO}_{2}$ curve of patients with GOLD stages III/IV showed a faster decline and slower recovery compared to patients with GOLD stages I/II. The $\mathrm{SpO}_{2}$ after the $6 \mathrm{MWT}$ of patients with GOLD stages I/II reached a full recovery within $1 \mathrm{~min}$.

Table 3. Multiple regression analysis of predictors of EID

\begin{tabular}{|c|c|c|c|c|}
\hline Variable & Coefficient B & B Coefficient $\beta$ & $\mathrm{t}$ & $\begin{array}{l}\mathrm{p} \\
\text { value }\end{array}$ \\
\hline Residual & 3.51 & & 3.04 & 0.003 \\
\hline BMI & -0.010 & -0.097 & -1.42 & 0.16 \\
\hline $\mathrm{FEV}_{1}, \%$ predicted & -0.012 & -0.48 & -5.03 & $<0.001$ \\
\hline DLCO, $\%$ predicted & -0.003 & -0.12 & -1.23 & 0.22 \\
\hline $\mathrm{SpO}_{2}$ at rest, $\%$ & -0.017 & -0.10 & -1.60 & 0.11 \\
\hline
\end{tabular}

Table 4. Accuracy of $\mathrm{FEV}_{1}$ levels as cutoff values for estimating EID

\begin{tabular}{lllllll}
\hline FEV $_{1}, \%$ predicted & 30 & 40 & 50 & 60 & 70 & 80 \\
\hline Sensitivity & 0.49 & 0.80 & 0.88 & 0.94 & 0.98 & 1 \\
Specificity & 0.92 & 0.76 & 0.71 & 0.49 & 0.32 & 0.12 \\
FPR & 0.08 & 0.23 & 0.29 & 0.51 & 0.68 & 0.88 \\
PPV & 0.90 & 0.84 & 0.83 & 0.75 & 0.70 & 0.65 \\
NPV & 0.53 & 0.70 & 0.79 & 0.85 & 0.90 & 1 \\
\hline
\end{tabular}

FPR $=$ False-positive rate $=1-$ specificity $; \mathrm{PPV}=$ positive predictive value; NPV = negative predictive value. 


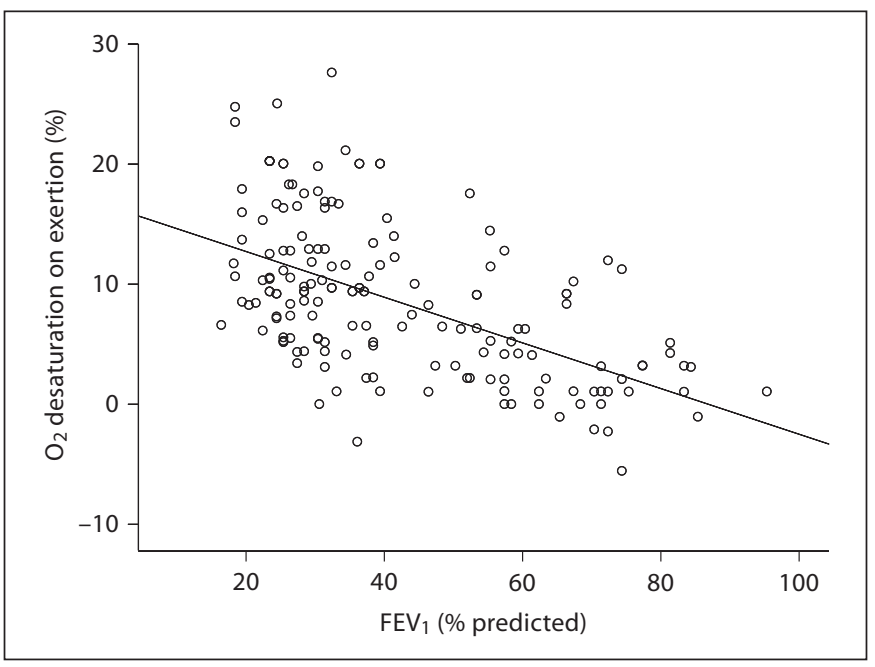

Fig. 3. Scatterplot showing the relationship between $\mathrm{FEV}_{1}$ (\%predicted) and exercise-induced desaturation on exertion in percent $(\mathrm{r}=-0.56, \mathrm{p}<0.001, \mathrm{n}=154)$.

Association between EID and Daily Physical Activity

Correlation analysis revealed that EID was more pronounced in patients with low daily activity as estimated by the average number of steps per day $(\mathrm{r}=-0.31, \mathrm{p}=$ $0.008)$.

\section{Discussion}

We found a high prevalence of EID in patients with COPD during the 6MWT. The $\mathrm{SpO}_{2}$ curve of patients with GOLD stages III/IV showed a faster decline and slower recovery compared to patients with GOLD stages I/II. It is possible to estimate the severity of EID using only $\mathrm{FEV}_{1}$. The positive predictive value of a threshold of $\mathrm{FEV}_{1}<50 \%$ was 0.83 and the negative predicting value of a threshold of $\mathrm{FEV}_{1} \geq 80 \%$ was 1.0. EID seems to have an impact on daily physical activity since we found that more severe EID was modestly associated with impaired ambulatory daily physical activity.

Hypoxemia both at rest [5] and during physical exercise [27] are important and common complications in patients with COPD. There are established criteria for prescribing oxygen therapy [10, 11]. The ATS/European Respiratory Society guidelines for the diagnosis and management of COPD recommend that oxygen therapy should be initiated if a patient's $\mathrm{SpO}_{2}$ reaches an arterial

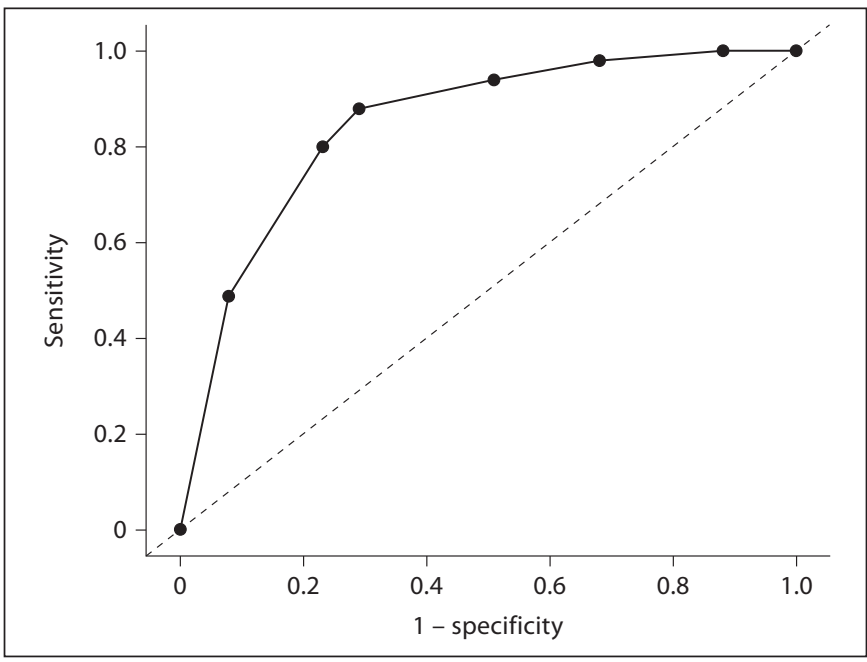

Fig. 4. ROC curve showing that the best combination of sensitivity and specificity occurred at an $\mathrm{FEV}_{1}$ value of $50 \%$ predicted (area under the ROC curve 0.85; $\mathrm{p}<0.001$ ): setting the threshold of $\mathrm{FEV}_{1}$ at $50 \%$ gives a sensitivity of 0.88 , a specificity of 0.71 and a likelihood ratio of 3.03 .

$\mathrm{SaO}_{2}$ of $<88 \%$ documented at rest or during exercise [10, 11]. However, for many COPD patients long-term oxygen therapy may fall short of guideline recommendations due to undiagnosed EID.

It has been postulated that episodic hypoxemia such as EID may have adverse consequences on morbidity and mortality. EID has been reported to be associated with increased mortality in patients with COPD $[13,14]$. In a study of the British Medical Research Council, patients with hypoxemia at rest receiving oxygen were compared with patients receiving no oxygen and the findings implied that oxygen therapy was associated with a significant reduction in mortality [28]. A second rationale for oxygen therapy is that dyspnea associated with EID may discourage COPD patients from exercise, promoting further deconditioning, and thus loss of pleasurable and productive activities. Acute administration of supplemental oxygen has been shown to improve ventilatory function and cardiopulmonary exercise capacity and decrease dyspnea in patients with COPD [29, 31]. In contrast, Moore et al. [30] found no improvement in dyspnea, quality of life and functional capacity after 12 weeks of oxygen therapy in COPD patients with exertional dyspnea.

The results of the present study show that the level of EID in patients with COPD deteriorates considerably with increasing severity of the disease. In this group of COPD patients, we found an unexpectedly large percent- 
age of patients (61.7\%) who experienced EID during the $6 \mathrm{MWT}$. Furthermore, we found that EID develops during the initial part (1st-4th minute) and reaches a plateau after the 4th minute during the 6MWT. The $\mathrm{SpO}_{2}$ curve of patients with GOLD stages III/IV showed a faster decline and slower recovery compared to patients with GOLD stages I/II. This may be because patients in GOLD stages III/IV are more likely to have a reduced $\mathrm{PaO}_{2}$ corresponding to the steeper part of the oxygen-hemoglobin dissociation curve, and thus small decreases in $\mathrm{PaO}_{2}$ (for example during exercise) are associated with relatively large declines in $\mathrm{SpO}_{2}$. These results are concordant with Troosters et al. [32], who found that $\mathrm{VO}_{2}$ (liters/min) showed a plateau after the $3 \mathrm{rd}$ min of the $6 \mathrm{MWT}$. The observed fast decline in $\mathrm{SpO}_{2}$ in patients with more severe COPD may be of clinical importance as it predicts the need for chronic domiciliary oxygen therapy [33]. At this point it should be mentioned that continuous pulse oximetry is necessary to accurately describe the dynamic changes in $\mathrm{SpO}_{2}$ during the 6MWT.

Based on the large percentage of patients who experienced EID during the 6MWT in this study, it may well be that EID is a common phenomenon during activities of daily life even in patients with milder forms of COPD. Supporting this hypothesis we found that EID was associated with daily physical activity in the present study. However, this modest association needs to be interpreted with caution as the step count provided by the device used may be underestimated when patients walk slowly [34].

Clinical criteria to predict EID may be particularly helpful to physicians working in primary care or in countries with limited resources to reduce the prevalence of unrecognized EID among patients with COPD without unnecessary diagnostic testing. A few previously published studies looked at whether pulmonary function and arterial blood gas measurements have the potential to predict the development of EID in patients with COPD $[15-17,19,20]$. Some of these studies found that $\mathrm{FEV}_{1}$, DLCO and resting $\mathrm{SpO}_{2}$ can be used as screening tests to predict EID $[12,13,19,20]$, but others failed to identify those or other variables as predictors $[5,15,18]$.

The only independent predictor of EID in the current study was $\mathrm{FEV}_{1}$ and the optimal cutoff value of $\mathrm{FEV}_{1}$ was at $50 \%$ (area under the ROC curve, $0.85 ; \mathrm{p}<0.001$ ). Owens et al. [20] found that a $\mathrm{FEV}_{1}$ value $\geq 55 \%$ was $100 \%$ predictive in excluding desaturation during exercise. However, our findings imply that a considerable proportion of patients with milder forms of COPD do experience EID (table 4). On the other hand, the results of the present study confirm that there is no need for uncomplicated patients with GOLD stage I to be tested for EID. In contrast, the high positive predictive value for a threshold of $\mathrm{FEV}_{1}<50 \%$ of 0.83 with a likelihood ratio of 3.03 underlines the importance of testing patients with COPD in GOLD stages III/IV for EID.

The present study has certain limitations that need to be taken into account. Pulse oximetry has been challenged as a poor measure of true arterial desaturation particularly during exercise $[35,36]$. However, there are now several oximeters available that have features to minimize motion artifacts and provide information on the signal strength. In addition, trends of arterial oxygen desaturation during physical exercise have been proven reliable and are generally accepted as a tool for prescribing oxygen therapy [37].

Furthermore, it should be stressed that we have not proven that oxygen supplementation in patients with COPD with EID will improve outcome. This may be particularly true in patients with mild EID and should be addressed in a randomized controlled interventional trial.

In conclusion, we found that there is a high prevalence of EID in patients with COPD and EID was associated with impaired daily physical activity. The level of EID in patients with COPD is associated with increasing severity of the disease, and it is possible to estimate exerciseinduced oxygen desaturation by using only $\mathrm{FEV}_{1}$. These findings may help to decide in which patients with COPD a 6MWT with continuous measurement of $\mathrm{SpO}_{2}$ should be performed.

\section{Financial Disclosure and Conflicts of Interest}

None of the authors has a conflict of interest related to the content of the manuscript.

References

1 Global Initiative for Chronic Obstructive Lung Disease: Global strategy for the diagnosis, management, and prevention of chronic obstructive pulmonary disease. Chron Respir Dis 2010;7:131-133.

-2 Simpson K, Killian K, McCartney N, Stubbing DG, Jones NL: Randomized controlled trial of weightlifting exercise in patients with chronic airflow limitation. Thorax 1992;47: 70-75.

- 3 Decramer M, Gosselink R, Troosters T, Verschueren M, Evers G: Muscle weakness is related to utilization of health care resources in COPD patients. Eur Respir J 1997; 10:417-423.

van Gestel/Clarenbach/Stöwhas/ Teschler/Russi/Teschler/Kohler 
-4 Garcia-Aymerich J, Lange P, Benet M, Schnohr P, Anto JM: Regular physical activity reduces hospital admission and mortality in chronic obstructive pulmonary disease: a population based cohort study. Thorax 2006; 61:772-778.

5 Freitag AP, Summers E, Hamilton AL: Behavior of arterial oxygen saturation during exercise in normal subjects and patients with pulmonary and cardiac impairment. Chest 1995;108:140S.

-6 Wright JL, Levy RD, Churg A: Pulmonary hypertension in chronic obstructive pulmonary disease: current theories of pathogenesis and their implications for treatment. Thorax 2005;60:605-609.

7 Maclay JD, McAllister DA, Macnee W: Cardiovascular risk in chronic obstructive pulmonary disease. Respirology 2007;12:634641.

$\checkmark 8$ Wagner PD: The biology of oxygen. Eur Respir J 2008;31:887-890.

-9 Pauwels RA, Buist AS, Calverley PM, Jenkins CR, Hurd SS, the GOLD Scientific Committee: Global strategy for the diagnosis, management, and prevention of chronic obstructive pulmonary disease. NHLBI/WHO Global Initiative for Chronic Obstructive Lung Disease (GOLD) Workshop summary. Am J Respir Crit Care Med 2001;163:1256 1276.

10 Celli BR, MacNee W, ATS/ERS Task Force: ATS/ERS Standards for the diagnosis and treatment of patients with COPD: a summary of the ATS/ERS position paper. Eur Respir J 2004;23:932-946.

- 11 Préfaut C, Durand F, Mucci P: Exercise-induced arterial hypoxemia in athletes: a review. Sports Med 2000;30:47-61.

-12 Stewart RI, Lewis CM: Arterial oxygenation and oxygen transport during exercise in patients with chronic obstructive pulmonary disease. Respiration 1986;49:161-169.

13 Kawakami Y, Terai T, Yamamoto H, Murao M: Exercise and oxygen inhalation relative to prognosis of chronic obstructive pulmonary disease. Chest 1982;81:182-188.

$\checkmark 14$ Van den Bergh V, Clement J, van de Woestijne KP: Course and prognosis of patients with advanced chronic obstructive pulmonary disease: evaluation by means of functional indices. Am J Med 1973;55:736-746.
5 Ries AL, Farrow JT, Clausen JL: Pulmonary function tests cannot predict exercise-induced hypoxemia in chronic obstructive pulmonary disease. Chest 1988;93:454-459.

16 Mak VHF, Bugler JR, Roberts CM, Spiro SG: Effect of arterial oxygen desaturation on six minute walk distance, perceived effort, and perceived breathlessness in patients with airflow limitation. Thorax 1993;48:33-38.

17 Knower MT, Dunagan DP, Adair NE, Chin $\mathrm{R}$ : Baseline oxygen saturation predicts exercise desaturation below prescription threshold in patients with chronic obstructive pulmonary disease. Arch Intern Med 2001;161: 732-736.

$\longrightarrow 18$ Woodcock AA, Gross ER, Geddes DM: Oxygen relieves breathlessness in 'pink puffers' Lancet 1981;1:907-909.

19 Jenkins S, Ceins N: Six-minute walk test: observed adverse events and oxygen desaturation in a large cohort of patients with chronic lung disease. Intern Med J 2011;41:416422.

20 Owens CR, Rogers RM, Pennock BE, Levin $D$ : The diffusing capacity as a predictor of arterial oxygen desaturation during exercise in patients with chronic obstructive pulmonary disease. N Engl J Med 1984;310:12181221.

21 Miller MR, Hankinson J, Brusasco V, Series 'ATS/ERS Task Force: Standardisation of spirometry. Eur Respir J 2005;26:319-338.

22 Miller MR, Crapo R, Hankinson J, Brusasco V, Burgos F, Casaburi R, Coates A, Enright P, van der Grinten CPM, Gustafsson P, Jensen R, Johnson DC, MacIntyre N, McKay R, Navajas D, Pedersen OF, Pellegrino R, Viegi G, Wanger J: General considerations for lung function testing. Eur Respir J 2005;26:153161.

23 American Thoracic Society: ATS statement: guidelines for the six-minute walk test. Am J Respir Crit Care Med 2002;166:111-117.

-24 Guyatt GH, Pugsley SO, Sullivan MJ, Thompson PJ, Berman L, Jones NJ: Effect of encouragement on walking test performance. Thorax 1984;39:818-822.

25 Tobin M: Respiratory monitoring. JAMA 1990;264:244-251.

26 Watz H, Waschki B, Boehme C, Claussen M, Meyer T, Magnussen H: Extrapulmonary effects of chronic obstructive pulmonary disease on physical activity - a cross-sectional study. Am J Respir Crit Care Med 2008;177: 743-751.
27 Panos RJ, Eschenbacher W: Exertional desaturation in patients with chronic obstructive pulmonary disease. COPD 2009;6:478487.

28 Report of the Medical Research Council Working Party: Long-term domiciliary oxygen therapy in chronic hypoxic cor pulmonale complicating chronic bronchitis and emphysema. Lancet 1981;1:681-685.

29 Ishimine A, Saito H, Nishimura M, Nakano T, Miyamoto K, Kawakami Y: Effect of supplemental oxygen on exercise performance in patients with chronic obstructive pulmonary disease and an arterial oxygen tension over 60 Torr. Nihon Kyobu Shikkan Gakkai Zasshi 1995;33:510-519.

30 Moore RP, Berlowitz DJ, Denehy L, Pretto JJ, Brazzala DJ, Sharpe K, Jackson B, McDonald CF: A randomised trial of domiciliary, ambulatory oxygen in patients with COPD and dyspnoea but without resting hypoxaemia. Thorax 2011;66:32-37.

31 Héraus N, Préfaut C, Durand F, Varray A: Does correction of exercise-induced desaturation by $\mathrm{O}_{2}$ always improve exercise tolerance in COPD? A preliminary study. Respir Med 2008;102:1276-1286.

32 Troosters T, Vilaro J, Rabinovich R, Casas A, Barbera JA, Rodriguez-Roisin R, Roca J: Physiological responses to the 6-min walk test in patients with chronic obstructive pulmonary disease. Eur Respir J 2002;20:564-569.

33 Garcia-Talavera I, Tauroni A, Trujillo JL, Pitti R, Eiroa LL, Aguirre-Jaime A, Sánchez A, Abreu J: Time to Desaturation Less Than One Minute Predicts the Need for Chronic Domiciliary Oxygen Therapy. Respir Care 2011;May 20. DOI: 10.4187/respcare.01164.

- 34 Hill K, Dolmage TE, Woon L: Measurement properties of the SenseWear armband in adults with chronic obstructive pulmonary disease. Thorax 2010;65:486-491.

- 35 McGovern JP, Sasse SA, Stansbury DW, Causing LA, Light RW: Comparison of oxygen desaturation by pulse oximetry and cooximetry during exercise testing in patients with COPD. Chest 1996;109:1151-1155.

-36 Petterson MT, Begnoche VL, Graybeal JM: The Effect of Motion on Pulse Oximetry and Its Clinical Significance. Anesth Analg 2007; 105(6 suppl):78-84.

37 Escourrou PJL, Delaperche MF, Visseaux A: Reliability of pulse oximetry during exercise in pulmonary patients. Chest 1990:97:635638 